\title{
Non-calcified pulmonary nodules detected in low-dose computed tomography lung cancer screening programs can be potential precursors of malignancy
}

\author{
Robert Dziedzic, Witold Rzyman \\ Department of Thoracic Surgery, Medical University of Gdansk, Gdansk, Poland \\ Correspondence to: Robert Dziedzic, MD, PhD. Department of Thoracic Surgery, Medical University of Gdansk, Sklodowska-Curie 3a St., 80-210 \\ Gdansk, Poland. Email: dziedzic@gumed.edu.pl.
}

Provenance and Peer Review: This article was commissioned by the editorial office, Quantitative Imaging in Medicine and Surgery. The article did not undergo external peer review.

Comment on: Pinsky P, Gierada DS. Long-term cancer risk associated with lung nodules observed on low-dose screening CT scans. Lung Cancer 2020;139:179-84.

Submitted Mar 11, 2020. Accepted for publication Mar 26, 2020.

doi: 10.21037/qims.2020.04.01

View this article at: http://dx.doi.org/10.21037/qims.2020.04.01

Non-specific pulmonary nodules detected in low-dose computed tomography (LDCT) lung cancer screening have been the subject of discussions for years. Lung nodules are detected in $20-50 \%$ of high-risk individuals undergoing lung cancer screening and may cause harm for patients due to the need for further CT surveillance or invasive procedures. A high proportion of detected non-specific pulmonary nodules is one of the drawbacks of lung cancer screening programs.

Between 2009-2011 in Gdańsk, Poland, we conducted a single-arm observational lung cancer screening program (1) for individuals at high risk of developing lung cancer, aged $50-75$, with at least 20 pack-years of smoking history. Among 8,649 people screened, nonspecific pulmonary nodules were found in $54 \%$ of participants and non-calcified nodules (NCNs) in 34\%. Lung cancer was diagnosed in $1.24 \%$ [107] of all participants (1).

Subsequently, to evaluate the lung cancer incidence in the study population in the 5 years follow-up we analyzed retrospectively the database of the Polish National Health Fund (pol. Narodowy Fundusz Zdrowia). During the 5 years of follow-up from the end of the screening program, lung cancer was detected in another 382 program participants, so in $4.42 \%$ of the whole cohort. The total number of program participants diagnosed with lung cancer was $488(5.65 \%)$ in the period $2009-2016$ and the mean annual lung cancer detection rate would have been $0.77 \%$ a year if the screening was continued (2).

Recently, in Lung Cancer, Pinsky and Gierada published an interesting article entitled "Long-term cancer risk associated with lung nodules observed on low-dose screening CT scans" (3). The authors subjected to a long observation LDCT arm participants of the National Lung Screening Trial (NLST) (4). The risk of lung cancer in trial participants with both a detected lung nodule in the baseline scan and new incidental findings during the followup has been evaluated.

Of the 26,309 subjects who underwent low-dose CT, $26.9 \%[7,090]$ had a NCN in the baseline examination. The analysis was also carried out from the perspective of specific lung lobes. Among 131,545 lung lobes, nodules were found in $7.2 \%[9,448]$ of them. More than $20 \%$ of these nodules had a diameter $\geq 8 \mathrm{~mm}$.

The main results were presented in rate-ratios (RRs), which were computed as the ratio of the lung cancer incidence rate in a NCN group divided by the lung incidence rate in a comparison group without NCN. Adjusted RRs for periods 0-4, 4-8 and 8-12 years of follow- 
up after the baseline CT were 5.1, 1.5 and 1.5 respectively. It means that the participants who had the NCN discovered in the baseline CT scan, had 5.1-, 1.5- and 1.5-times higher risk of lung cancer compared to individuals without the pulmonary nodules in the period of the first 4,8 and 12 years of follow-up, respectively. For the lobe level perspective, the rates were even higher. Lobes with pulmonary nodules had 14.7-, 2.6-, 2.2-times higher rate of lung cancer compared to lobes without NCNs in periods $0-4,4-8$ and $8-12$ years, respectively.

Despite the publication of numerous guidelines for the management of accidentally detected pulmonary nodules, such as Lung-RADS, Fleischner Society Guidelines or BTS $(5,6)$, NCNs remains a problem in everyday practice. Solid lung nodules should be observed for at least 2-3 years. If they do not progress, the observation may be terminated in the non-screening circumstances. For non-solid nodules, this period should be extended up to 5 years. In the view of the results of the study published by Pinsky and Gierada, it is doubtful whether a period of 2 or even 3 years of followup observation is sufficient for solid nodules. High-risk individuals participating in the screening program will normally undergo long term observation on the annual basis. The problem concerns individuals who do not meet the criteria of the high-risk and are not covered by screening, then often we have to make difficult decisions to terminate the observation.

Since the screening for lung cancer has been justified, the main question is how to optimize the screening to achieve high cost-effectiveness and minimal harm for the screenees. What role patient profiling play according to individual risk prediction models (7)? What is the optimal time interval between screening rounds? Should screening protocols vary for females and males? Should volumetric evaluation be routinely used in screening? Recently the results of the NELSON study have been published (8) showing that CT screening with nodule evaluation based on volumetric measurements not only reduces mortality from lung cancer but also reduces some negative aspects of screening, i.e., reduces the rates of false-positive results and reduces the rates of unnecessary diagnostic procedures. This study showed that annual screening is more effective than biannual in terms of medical results but of course less cost-effective. The study of Pinsky and Gierada shows us that perhaps an individual approach taking into account the presence or absence of nodules in the baseline study can be considered as a criterion determining the frequency of screening in heavy smokers.
In conclusion, Pinsky and Gierada proved that nodules detected in the low-dose lung cancer screening can be a predictor of lung cancer even 10 years or more after the baseline LDCT. Non-calcified lung nodules, at least some subset of them, may probably be the precursors of lung cancer. However, the nature of this observation remains unexplained. We do not know if some of the nodules are precursors of lung cancer or individuals who have nodules are more likely to develop cancer, not necessarily at the site of the nodules in the baseline study. This requires a very meticulous retrospective analysis of subsequent scans of persons subjected to screening in whom cancer occurred after several years of observation. In the era of intensive research in this field, artificial intelligence can be very helpful in explaining this phenomenon.

\section{Acknowledgments}

Funding: None.

\section{Footnote}

Conflicts of Interest: Both authors have completed the ICMJE uniform disclosure form (available at http://dx.doi. org/10.21037/qims.2020.04.01). The authors have no conflicts of interest to declare.

Open Access Statement: This is an Open Access article distributed in accordance with the Creative Commons Attribution-NonCommercial-NoDerivs 4.0 International License (CC BY-NC-ND 4.0), which permits the noncommercial replication and distribution of the article with the strict proviso that no changes or edits are made and the original work is properly cited (including links to both the formal publication through the relevant DOI and the license). See: https://creativecommons.org/licenses/by-nc-nd/4.0/.

\section{References}

1. Rzyman W, Dziedzic R, Jelitto-Górska M, Biadacz I, Książek J, Siebert J, Zdrojewski T, Studniarek M. Results of an open-access lung cancer screening program with low-dose computed tomography: the Gdańsk experience. Pol Arch Med Wewn 2015;125:232-9.

2. Ostrowski M, Marczyk M, Dziedzic R, Jelitto-Górska M, Marjański T, Pisiak S, Jędrzejczyk T, Polańska J, Zdrojewski T, Wojtyniak B, Rzyman W. Lung cancer survival and comorbidities in lung cancer screening 
participants of the Gdańsk screening cohort. Eur J Public Health 2019;29:1114-7.

3. Pinsky P, Gierada DS. Long-term cancer risk associated with lung nodules observed on low-dose screening CT scans. Lung Cancer 2020;139:179-84.

4. National Lung Screening Trial Research Team, Aberle DR, Adams AM, Berg CD, Black WC, Clapp JD, Fagerstrom RM, Gareen IF, Gatsonis C, Marcus PM, Sicks JD. Reduced lung-cancer mortality with low-dose computed tomographic screening. N Engl J Med 2011;365:395-409.

5. MacMahon H, Naidich DP, Goo JM, Lee KS, Leung ANC, Mayo JR, Mehta AC, Ohno Y, Powell CA, Prokop M, Rubin GD, Schaefer-Prokop CM, Travis WD, Van Schil PE, Bankier AA. Guidelines for management of incidental pulmonary nodules detected on CT images: from the Fleischner Society 2017. Radiology 2017;284:228-43.

6. Callister ME, Baldwin DR, Akram AR, Barnard S, Cane P, Draffan J, Franks K, Gleeson F, Graham R, Malhotra

Cite this article as: Dziedzic R, Rzyman W. Non-calcified pulmonary nodules detected in low-dose computed tomography lung cancer screening programs can be potential precursors of malignancy. Quant Imaging Med Surg 2020;10(5):1179-1181. doi: 10.21037/qims.2020.04.01
P, Prokop M, Rodger K, Subesinghe M, Waller D, Woolhouse I; British Thoracic Society Pulmonary Nodule Guideline Development Group; British Thoracic Society Standards of Care Committee. British Thoracic Society guidelines for the investigation and management of pulmonary nodules. Thorax 2015;70 Suppl 2:ii1-54.

7. Gray EP, Teare MD, Stevens J, Archer R. Risk prediction models for lung cancer: a systematic review. Clin Lung Cancer 2016;17:95-106.

8. de Koning HJ, van der Aalst CM, de Jong PA, Scholten ET, Nackaerts K, Heuvelmans MA, Lammers JJ, Weenink C, Yousaf-Khan U, Horeweg N, van 't Westeinde S, Prokop M, Mali WP, Mohamed Hoesein FAA, van Ooijen PMA, Aerts JGJV, den Bakker MA, Thunnissen E, Verschakelen J, Vliegenthart R, Walter JE, Ten Haaf K, Groen HJM, Oudkerk M. Reduced Lung-Cancer Mortality with Volume CT Screening in a Randomized Trial. N Engl J Med 2020;382:503-13. 